TI 2003-029/2

Tinbergen Institute Discussion Paper

On Taxation in a Two-Sector Endogenous Growth Model with Endogenous Labor Supply

Paul A. de Hek 


\section{Tinbergen Institute}

The Tinbergen Institute is the institute for economic research of the Erasmus Universiteit Rotterdam, Universiteit van Amsterdam, and Vrije Universiteit Amsterdam.

Tinbergen Institute Amsterdam

Roetersstraat 31

1018 WB Amsterdam

The Netherlands

Tel.: $\quad+31(0) 205513500$

Fax: $\quad+31(0) 205513555$

Tinbergen Institute Rotterdam

Burg. Oudlaan 50

3062 PA Rotterdam

The Netherlands

Tel.: $\quad+31(0) 104088900$

Fax: $\quad+31(0) 104089031$

Please send questions and/or remarks of nonscientific nature to driessen@tinbergen.nl.

Most TI discussion papers can be downloaded at http://www.tinbergen.nl. 


\title{
On Taxation in a Two-Sector Endogenous Growth Model with Endogenous Labor Supply
}

\author{
Paul A. de Hek* \\ Erasmus University Rotterdam and Tinbergen Institute
}

March 27, 2003

\begin{abstract}
This paper examines the effects of taxation on long-run growth in a two-sector endogenous growth model with (i) physical capital as an input in the education sector and (ii) leisure as an additional argument in the utility function. The analysis of the effects of taxation including income taxation, capital income taxation and labor income taxation - distinguishes between the case with a unique (interior) balanced growth path and the case with multiple balanced growth paths. Due to the flexibility of labor supply, taxation of income may induce agents to spend more or less time on leisure activities. In the case of income taxation, where capital and labor income are taxed equally, the resulting effect on the growth rate is negative. The contribution of endogenous leisure is confined to reducing or increasing the size of the effect on the growth rate. If only capital income is taxed, the direction of the effect may reverse. In that case, the positive effect of the increase in total non-leisure time dominates the direct negative effect, implying that capital taxation increases the long-run growth rate.
\end{abstract}

JEL Classification: E20, H20, J22, J24, O41

*Address for correspondence: Paul de Hek, Department of Economics, H7-09, Erasmus University Rotterdam, P.O.Box 1738, 3000 DR Rotterdam, The Netherlands. Email: pdehek@few.eur.nl. Financial support from the Netherlands Organisation for Scientific Research (NWO) is gratefully acknowledged. 


\section{Introduction}

This paper examines the effect of taxation on long-run growth in a twosector endogenous growth model with leisure as an additional argument in the utility function. Endogenizing labor supply through leisure-dependent utility in models of economic growth has some interesting implications for the dynamics of these models, see e.g. Ladrón-de-Guevara et al. (1997) and De Hek $(1998,1999)$. The present analysis shows that the model may have multiple balanced growth paths, depending on the values of the parameters. The analysis of the effects of taxation, including income taxation, capital income taxation and labor income taxation, therefore distinguishes between the case with a unique (interior) balanced growth path (BGP) and the case with multiple balanced growth paths.

In the case of a unique equilibrium, the analysis shows that, like in the case without leisure-dependent utility, taxation of income has a negative effect on the long-run growth rate. However, depending on the relative importance of substitution and income effects, a tax on income leads to a rise or fall in the time spent on leisure activities, which in turn increases respectively reduces the size of the negative effect on growth. Furthermore, contrary to the case without leisure-dependent utility, a tax on capital income may have a positive effect on the long-run growth rate. The intuition behind this effect is that, compared to a tax on income, a tax on capital income induces more time spent on production (capital accumulation) and human capital accumulation, because labor (time) is not taxed. Hence, time spent on leisure activities increases. It is shown that, under sensible parameter configurations, the positive effect of higher total non-leisure time outweighs the (direct) negative effect on growth of taxation. Finally, concerning the case with a unique balanced growth path, the analysis shows that a tax on labor income has a negative effect on the long-run growth rate.

The existence of multiple balanced growth paths is proved by showing that under some parameter configurations there exist three BGP's. A necessary condition for the existence of multiple BGP's is established and the stability of the BGP's is determined numerically. One of these BGP's is unstable while the other two BGP's are stable. The value of the ratio of physical to human capital determines which of the stable BGP's will be reached, the relatively high or relatively low growth BGP. A higher income tax rate in this setting implies a lower ratio of physical to human capital in the unstable BGP, which implies that a smaller set of values of the ratio of physical to human capital will converge to the 'high growth' BGP. In addition, the growth rate in the high growth BGP decreases.

The effects of income taxation in the context of a two-sector endogenous 
growth model have been examined before by many authors. Some of these studies use numerical simulations of calibrated models to calculate the effect of tax reform on growth, e.g. Lucas (1990), Jones, Manuelli and Rossi (1993), Stokey and Rebelo (1995) and Hendricks (1999). Others, like Chamley (1992) and Mino (1996), examine analytically the effect of (capital) income taxation on growth. Almost all these studies conclude that a (capital) income tax is bad for growth. An exception is Uhlig and Yanagawa (1996) who show that higher capital income taxes may lead to faster growth in an overlapping generations economy with endogenous growth. The reason for this positive effect is however entirely different from the reason for a similar positive effect in the present paper. They assume that labor income is paid mostly to the young while capital income accrues mostly to the old. This implies that a higher capital income tax, accompanied with a lower labor income tax, leaves the young with more income out of which to save. If the interest elasticity of savings is sufficiently low, the net effect on savings and, therefore, on growth is positive.

The analysis in the present paper is closely related to the analyses in Rebelo (1991), Ladrón-de-Guevara et al. (1997) and Ortigueira (1998). In fact, the model in the present paper is the same as Rebelo's model with an endogenous leisure choice (Rebelo, 1991, section III). Due to analytical difficulties, Rebelo confines his analysis of the effect of income taxation on the rate of growth to numerical simulations. These simulations indicate that taxing income has a negative effect on the growth rate. The analysis in this paper shows analytically that this is true. Ladrón-de-Guevara et al. (1997) establishes that there could be multiple balanced growth paths in the human capital accumulation model of Lucas (1988) if leisure is endogenously determined. The present analysis extends this result to the more general two-sector endogenous growth model, where physical capital is included as an input of the educational sector. Ortigueira (1998) studies the effects of labor and capital income taxation on the transitional dynamics to the balanced growth path. He considers both the case of physical capital in the education sector and leisure as an additional argument in the utility function as two separate extensions of the basic model.

The main innovation of this paper relative to the previous literature is to combine physical capital as an input in the educational sector and leisure as an additional argument in the utility function. Previous work has studied models with either the former or the latter feature, but not with both. The present study first shows that the combination of both features leaves the possibility of multiple balanced growth paths intact, compared to the model with endogenous leisure but without capital in the education sector. Second, the finding that endogenous leisure may strengthen or weaken the effect of 
income taxes on growth, but does not reverse the sign, does depend on this combination. The positive effect of capital income taxes on growth is however shown to be a consequence of the labor-leisure choice. The inclusion of capital as an input in the education sector actually reduces this possibility.

The paper is organized as follows. Section 2 describes the model and its solution, including the possibility of multiple BGP's. Section 3 analyses the effects of taxation on long-run growth, including income, capital-income and labor-income taxation, both in the unique BGP case and the multiple BGP's case. A summary is given in section 4 .

\section{The Model}

Following Rebelo (1991, section III), the model consists of two sectors with different technologies for production and education. A fraction $\phi$ of total capital $K$ together with $N H$ efficiency units of labor, where $N$ is the fraction of time allocated to labor and $H$ the stock of human capital, are used for the production of goods, i.e.,

$$
Y(t)=A(\phi(t) K(t))^{1-\gamma}(N(t) H(t))^{\gamma},
$$

where $A>0$ and $0<\gamma<1$ are parameters. Profit maximization implies that in equilibrium firms must pay each production factor its marginal productivity:

$$
\begin{gathered}
r(t)=(1-\gamma) A(\phi(t) K(t))^{-\gamma}(N(t) H(t))^{\gamma}, \\
w(t)=\gamma A(\phi(t) K(t))^{1-\gamma}(N(t) H(t))^{\gamma-1},
\end{gathered}
$$

where $r$ is the interest rate and $w$ the wage rate. The government imposes flat-rate taxes on capital income, $\tau_{r}$, and labor income, $\tau_{w}$. The analysis will be undertaken in a closed economy context, but, as noted by Rebelo (1991), is valid in a world of open economies connected by international capital markets if all countries follow the worldwide tax system. Furthermore, to focus on the effects of taxation, government revenues do not affect the marginal utility of private consumption and leisure or the production possibilities of the private sector. Under these assumptions, capital accumulation takes place according to 


$$
\dot{K}(t)=\left(1-\tau_{r}\right) r(t) \phi(t) K(t)+\left(1-\tau_{w}\right) w(t) N(t) H(t)-\delta K(t)-C(t),
$$

where $\delta$ is the depreciation rate of capital and $C$ aggregate consumption.

Human capital accumulation takes place by combining the remaining fraction $(1-\phi)$ of the capital stock with $(1-N-L) H$ efficiency units of labor, where $L$ is the fraction of the time used for leisure activities. The human capital stock depreciates at the same rate $\delta$ as the physical capital stock. This leads to the following human capital accumulation equation:

$$
\dot{H}(t)=B[(1-\phi(t)) K(t)]^{1-\beta}[(1-N(t)-L(t)) H(t)]^{\beta}-\delta H(t),
$$

where $B>0$ and $0<\beta<1$ are parameters.

In the presence of an endogenous leisure choice, the preferences have to be such that in equilibrium the rate of growth of consumption and the allocations of time between work, leisure and human capital accumulation are constant. The following utility function is used throughout the paper ${ }^{1}$ :

$$
U(C, L)=\frac{\left(C^{\alpha} L^{1-\alpha}\right)^{1-\sigma}-1}{1-\sigma},
$$

for $\sigma>0(1 / \sigma$ is the elasticity of intertemporal substitution). This leads to the following optimization problem for the economy,

$$
\operatorname{Max}_{C(t), L(t), N(t), \phi(t)} \int_{0}^{\infty} e^{-\rho t} U(C(t), L(t)) d t
$$

subject to equations (4) and (5), and such that $C(t) \geq 0, K(t) \geq 0, H(t) \geq 0$, $0 \leq L(t) \leq 1,0 \leq N(t) \leq 1,0 \leq L(t)+N(t) \leq 1,0 \leq \phi(t) \leq 1, K(0), H(0)$ given. The parameter $\rho$ reflects the time preference of the economy.

In order to have different technologies for production and education, $\gamma$ and $\beta$ should be different. The most plausible case is that the goods sector is relatively intensive in physical capital while the educational sector is relatively intensive in human capital, i.e. $\gamma<\beta$. In most models with human capital accumulation $\beta$ is chosen to be one, as in Lucas (1988) and Ladrón-de-Guevara et al. (1997).

First, in a competitive equilibrium, the allocation of both physical and human capital across the two sectors is such that the marginal products of the

\footnotetext{
${ }^{1}$ See King, Plosser and Rebelo (1988) for a derivation of the class of utility functions from which this function is taken.
} 
two types of capital (measured in terms of units of physical capital) should be equated in the two sectors, i.e.,

$$
\left(1-\tau_{r}\right) r=q(1-\beta) B[(1-\phi) K]^{-\beta}[(1-N-L) H]^{\beta}
$$

and

$$
\left(1-\tau_{w}\right) w=q \beta B[(1-\phi) K]^{1-\beta}[(1-N-L) H]^{\beta-1},
$$

where $q$ is the relative value of human capital in terms of physical capital. Second, the return from investing one unit in physical capital should be the same as the return from investing $1 / q$ units in human capital. Hence,

$$
\left(1-\tau_{r}\right) r-\delta=\beta B[(1-\phi) K]^{1-\beta}[(1-N-L) H]^{\beta-1}(1-L)-\delta+\frac{\dot{q}}{q}
$$

Third, the optimal growth rate of consumption, given the interest rate, is

$$
\frac{\dot{c}}{c}=\frac{\left(1-\tau_{r}\right) r-\delta-\rho}{\sigma_{\alpha}}
$$

with $\sigma_{\alpha}=1-(1-\sigma) \alpha$. Last, the optimal allocation of time between leisure and non-leisure activities requires that the marginal utility of leisure equals the marginal productivity of non-leisure time measured in terms of utility of forgone consumption,

$$
\left(C^{\alpha} L^{1-\alpha}\right)^{-\sigma}(1-\alpha) C^{\alpha} L^{-\alpha}=\lambda q \beta B[(1-\phi) K]^{1-\beta}[(1-N-L) H]^{\beta-1} H,
$$

where $\lambda$ is the current-value shadow price of the capital stock. The derivation of equations (11) and (12) is given in appendix 5.1.

\subsection{The balanced growth path}

In a balanced growth path $C, K$ and $H$ grow at constant rates, while $\phi, N$ and $L$ remain constant. In particular, it follows that $\dot{C} / C=\dot{K} / K=\dot{H} / H \equiv g$. If we define $x \equiv K / H$ and $z \equiv C / H$, then this implies that, along a balanced growth path, $\dot{x}=0$ and $\dot{z}=0$. Using equations (4) and (5), the $\dot{x}=0$ equation is given by

$$
\left(1-\tau_{r}\right) r \phi+\left(1-\tau_{w}\right) w \frac{N}{x}-\frac{C}{K}=B(1-\phi)^{1-\beta}(1-N-L)^{\beta} x^{1-\beta} .
$$


Similarly, by equations (5) and (11), the $\dot{z}=0$ equation can be written as

$$
\frac{\left(1-\tau_{r}\right) r-\delta-\rho}{\sigma_{\alpha}}=B(1-\phi)^{1-\beta}(1-N-L)^{\beta} x^{1-\beta}-\delta .
$$

Furthermore, equations (8), (9), (10) and (12), together with the fact that $\dot{q}=0$ in a balanced growth path, imply that

$$
\begin{gathered}
\frac{1-\tau_{w}}{1-\tau_{r}} \frac{\gamma}{1-\gamma} \frac{\phi}{N}=\frac{\beta}{1-\beta} \frac{1-\phi}{1-N-L}, \\
\left(1-\tau_{r}\right)(1-\gamma) A\left[\frac{\phi}{N} x\right]^{-\gamma}=\beta B\left[\frac{(1-\phi)}{1-N-L} x\right]^{1-\beta}(1-L), \\
(1-\alpha) z=\alpha \beta B\left[\frac{(1-\phi)}{1-N-L} x\right]^{1-\beta} L .
\end{gathered}
$$

This system of equations, consisting of the equations (13)-(17), characterizes a balanced growth path. As is shown in appendix 5.2, the solution to this system involves the solution to the next two equations in the two unknown variables $N$ and $L$ :

$$
\begin{gathered}
(1-\gamma)(1-T \psi) N^{2}+ \\
+(1-L)\{\beta(1-\gamma+T \gamma)-(1-\gamma)(1-2 T \psi)\} N+ \\
-T(1-L)\left\{(1-\gamma) \psi(1-L)+\frac{\alpha \beta \gamma}{1-\alpha} L\right\}=0, \\
N=\frac{\sigma_{\alpha}-\beta}{\sigma_{\alpha}}(1-L)+\frac{\left(\rho+\left(1-\sigma_{\alpha}\right) \delta\right)(T \psi)^{-(1-\nu)(1-\beta)} \beta^{\nu}}{\sigma_{\alpha} B^{1-\nu}\left[\left(1-\tau_{r}\right) A(1-\gamma)\right]^{\nu}}(1-L)^{\nu},
\end{gathered}
$$

with $\psi \equiv \frac{\gamma(1-\beta)}{\beta(1-\gamma)}<1, T \equiv \frac{1-\tau_{w}}{1-\tau_{r}}$ and $\nu \equiv \frac{1-\beta}{1-\beta+\gamma}<1$. The first equation derives from the $\dot{x}=0$ equation, whereas the second equation derives from the $\dot{z}=0$ equation. To solve this reduced system of two equations, notice that the first equation can be written as $a N^{2}+b(L) N+c(L)$, with $c(L)<0$. Hence, $N$ can be expressed as a function of $L$, say $N=f(L)$. Similarly, equation (19) expresses $N$ as a function of $L$, say $N=h(L)$. Therefore we have a balanced growth path if $f(L)=h(L)$.

To keep the analysis clear, we impose the following condition: 
Condition $1 T \psi<1$.

The reason for imposing this condition is that this ensures that $a>0$, which implies that (i) the discriminant $\left(b^{2}-4 a c\right)$ is always positive (hence, there are only real solutions) and (ii) only one of the two solutions is positive. Moreover, it is not only a device to establish a unique positive solution, it is also an empirically plausible condition. As $\psi$ lies between 0 and 1 , the condition requires $T$ to be less than some value larger than one. E.g. if $\gamma=2 / 3$ (consistent with the usual data on labor's share of income) and $\beta=3 / 4(>\gamma)$, the condition requires $T$ to be less than $3 / 2$. Concerning the empirical evidence, Carey and Tchilinguirian (2000) construct average effective tax rates on both capital and labor income for the OECD countries, which are reported in table 1 . The last column shows the resulting values of $T$. It follows that 14 out of 21 countries have a $T$ smaller than 1 and all reported countries have a $T$ that is smaller than $3 / 2$. Hence, the condition is likely to be satisfied in reality. Notice that this condition is automatically satisfied if $\beta=1$ (as this implies that $\psi=0$ ).

\subsection{The possibility of multiple balanced growth paths}

In this section we shortly review the possibility of having multiple balanced growth paths in this model. First, it turns out that there is a necessary condition for the existence of more than one balanced growth path. This necessary condition derives from the fact that a balanced growth path is characterized by the equality of two functions of $L, f(L)$ and $h(L)$. First it is shown that $f(L)$ is strictly concave. Since a strictly concave function has at most two intersections with a convex function, and because $f(1)=$ $h(1)$ is one of the intersections, there will be at most one interior solution if $h(L)$ is convex. Hence, convexity of $h(L)$ excludes the possibility of multiple balanced growth paths. This leads to the next proposition.

Proposition 1 Let Condition 1 hold. A necessary condition for the existence of multiple balanced growth paths is that $\sigma<1+\frac{\rho}{\alpha \delta}$.

Proof. See appendix 5.5.1.

Is it likely that this condition holds in reality, or not? Given plausible values of the relevant parameters $-0<\rho<0.1,0<\delta<0.1$ and $0 \leq \alpha<1$ and the empirically estimated range of values for $\sigma$ - usually $\sigma$ is estimated somewhere between 1 and 5 - the comparison could come out either way.

Furthermore, if the condition holds, this does not imply that there are multiple balanced growth paths, as it is only a necessary condition. Given 
the complexity of the model, to find out whether it is actually possible to have multiple BGP's we resort to a numerical analysis. It turns out that it is possible to have more than one balanced growth path, as can be seen in figure 1. This figure shows the existence of three BGP's. BGP 1 and BGP 2 are interior, while BGP 3 is a non-interior balanced growth path (in which $N+L=1$ ). See appendix 5.3 for a proof that the non-interior BGP is characterized by $f(L)=1-L$ (i.e., it lies on the point of intersection of $N=f(L)$ and $N=1-L)$.

The existence of multiple balanced growth paths raises the question of the stability properties of the BGP's. Due to the complexity of the dynamical system, we investigated the stability of the BGP's numerically (see appendix 5.4). That analysis implies that BGP 2 is unstable, while BGP 1 and BGP 3 are stable. Let $x_{i}(i=1,2,3)$ denote the capital-human capital ratio at BGP $i$. Then, given some initial value $x_{0}\left(\neq x_{2}\right)$ there are $z_{0}, N_{0}, L_{0}$ and $\phi_{0}$ such that $\left\{x_{0}, z_{0}, N_{0}, L_{0}, \phi_{0}\right\}$ lies on a stable manifold and $x_{0}$ converges to either $x_{1}$ or $x_{3}$, depending on the specific value of $x_{0}$. The next lemma implies that along the curve of $f(L)$ a higher value of $L$ is accompanied with a higher capital-human capital ratio.

Lemma 2 Let Condition 1 hold and let $x(L, N)$ denote the optimal capitalhuman capital ratio as a function of $L$ and $N$. Then $\frac{\partial x(L, f(L))}{\partial L}>0$.

Proof. See appendix 5.5.2.

From this Lemma we may conclude that - given the stability properties implied by the numerical analysis - if $x_{0}$ is smaller than $x_{2}$ it converges to $x_{1}$ and if $x_{0}$ is larger than $x_{2}$ it converges to $x_{3}$. Furthermore, as will be apparent from the equation describing the growth rate of the economy as a function of leisure (see equation 20), more leisure lowers the growth rate on a balanced growth path. Thus, an economy with a relatively high human capital stock will converge to the 'high-growth' BGP, while an economy endowed with a relatively low human capital stock will end up in the 'low-growth' BGP (in which the growth rate is actually negative if the depreciation rate $\delta$ is positive).

As a last remark, it should be noted that the existence of multiple balanced growth paths relies on the presence of a labor-leisure choice, i.e. $0<$ $\alpha<1$. If $\alpha=1$, the model reduces to the basic two-sector endogenous growth model as described by Rebelo (1991, section III A), which has a unique interior solution. 


\section{The effects of taxation}

This section analyses the effects of taxation - income taxation, labor income taxation and capital income taxation - on the long-run growth rate. We distinguish two separate cases, one with a unique interior balanced growth path and one with multiple balanced growth paths. ${ }^{2}$ The effects critically depend on which of the cases apply.

\subsection{Unique interior balanced growth path}

\subsubsection{Income taxation}

Taxing (total) income implies that both tax rates are equal, i.e. $\tau_{w}=\tau_{r} \equiv \tau$ and $T=1$. To find the effect of taxation on the long-run growth rate we first write the growth rate, $g$, as a function of $L$,

$$
g(L)=G\left(1-\tau_{r}\right)^{(1-\gamma) \nu}\left(1-\tau_{w}\right)^{\gamma \nu}(1-L)^{1-\nu}-\frac{\rho+\delta}{\sigma_{\alpha}}
$$

with $G=\psi^{(1-\beta)(1-\nu)}(\beta B)^{1-\nu}((1-\gamma) A)^{\nu} / \sigma_{\alpha}$. See appendix 5.6 for a derivation of this result. Notice that this expression for the growth rate reduces to the growth rate in Rebelo (1991, equation 14) if $\alpha=1$.

This equation for the growth rate shows that, if both tax rates are equalized to $\tau$, the tax rate has a direct negative effect on the growth rate of $(1-\tau)^{\nu}$. Moreover, the tax rate also has an indirect effect on the growth rate through the effect on leisure. The direct effect consists of three separate effects. First, taxation takes resources away from a productive sector (the capital production sector) to use it in some unproductive way. Second, income taxation reduces the marginal products of capital and labor in the production of capital (see equation 4), inducing the economy to shift resources from capital production to human capital production (and to leisure activities, but this is part of the indirect effect). Third, the income effect resulting from taxing income implies that more capital and more time will be devoted to the production of capital. As noted above, these three effects taken together, apart from the (indirect) effect on total working time, affect the growth rate negatively.

The analysis above implies that the determination of the overall effect of an income tax on the long-run growth rate involves the effect of the tax rate on the equilibrium value of leisure. To find this latter effect, notice that,

\footnotetext{
${ }^{2}$ If $h(0)<f(0)$ it may happen that there is one interior BGP. However, that BGP will be unstable and the economy will converge to one of the two non-interior BGP's. This situation, therefore, falls into the category of multiple BGP's.
} 
since $T=1$, the function $f(L)$ is not affected by a change in the tax rate $\tau$. The function $h(L)$, on the contrary, is affected by a change of the tax rate. In particular, the nature of this effect (positive or negative) depends on the earlier encountered comparison between $\sigma$ and $1+\rho /(\alpha \delta)$ : An increase in $\tau$ induces a positive shift of $h(L)$ if $\sigma<1+\rho /(\alpha \delta)$ and a negative shift if $\sigma>1+\rho /(\alpha \delta)$. (See figure 2 for an example of the latter effect.) Hence, higher income taxes lead to a new balanced growth path with more or less time spent on leisure activities, depending on the relative value of $\sigma$, the inverse of the elasticity of intertemporal substitution (EIS). Intuitively, the higher $\sigma$, the lower the EIS and the more anxious agents are to smooth their consumption over time and, hence, the stronger the income effect. As a result, at a relatively high level of $\sigma$ the income effect dominates the substitution effect, leading to less time spent on leisure activities.

Spending less time on leisure activities and, hence, more time on working, either to produce output (and capital) or to produce human capital, has obviously a positive effect on the growth rate, as is also clear from equation (20). This raises the question whether this (indirect) positive effect could be stronger than the (direct) negative effect. Analyzing the derivative of $g(L)$ with respect to the tax rate $\tau$, however, reveals that this situation cannot arise.

Proposition 3 Let Condition 1 hold. Suppose that there is a unique interior $B G P$. Let $\tau_{w}=\tau_{r} \equiv \tau$. Then an increase in the tax rate induces a decline the long-run rate of growth.

Proof. See appendix 5.5.3.

Hence, taxing both labor income and capital income equally reduces the long-run growth rate. Compared to the situation with a fixed labor supply, the negative effect of income taxation on the long-run growth rate is either stronger (i.e. more negative) in the case of a relatively large EIS, which leads to more time spent on leisure activities, or weaker (i.e. less negative) in the case of a relatively small EIS, which leads to less time spent on leisure activities. Smith (1996) finds a similar but opposite effect of introducing uncertainty into the model. In a stochastic growth model, he finds that: (i) If the EIS is small, an increase in the tax rate reduces growth more than predicted by non-stochastic models; (ii) If the EIS is large, the long-run growth rate decreases by less than predicted by non-stochastic models. ${ }^{3}$

\footnotetext{
${ }^{3}$ The comparison between the effects of uncertainty in Smith (1996) and the effects of endogenous labor supply in the present paper on the impact of tax rates on long-run growth can de drawn even further. Both analyses show that it is actually possible for a tax increase to increase growth (see section 3.1.2 in the present paper).
} 
If $\beta=1$, that is, if human capital accumulation is independent from physical capital, the expression for the growth rate, as given by equation (20), changes to

$$
g(L)=\frac{B}{\sigma_{\alpha}}(1-L)-\frac{\rho+\delta}{\sigma_{\alpha}} .
$$

This implies that taxes have no direct effect on the long-run growth rate. Moreover, it can easily be shown that in this case the function $h(L)$ is independent from any tax rate (see appendix 5.2). As a result, income taxation has no indirect effect on the growth rate either. Hence, the finding that endogenous leisure may strengthen or weaken the effect of income taxes on growth, but does not reverse the sign, depends on the combination of both physical capital in the educational sector and leisure as an additional argument in the utility function.

\subsubsection{Capital income taxation}

In this section we analyze the effect of a capital income tax on the long-run growth rate. For simplicity, let us start with the case in which capital is not an input in the education sector, i.e. $\beta=1$. Hence, the capital income tax rate has no direct effect on the growth rate (see equation 21). A change in the time spent on leisure, then, directly translates into a change in the growth rate. To find the indirect effect of the tax rate through the effect on leisure, we need to examine, as in the previous section, the effect of the tax rate on the functions $f(L)$ and $h(L)$, which are (implicitly) given in appendix 5.2. First, notice that $f(L)$ only depends on the capital income tax rate, $\tau_{r}$, through $T$. The derivative of $f(L)$ with respect to $T$ can be derived from total differentiation of equation (33). As a result,

$$
\frac{\partial f(L)}{\partial T} \propto \gamma(1-L)\left[\frac{\alpha}{1-\alpha} L-f(L)\right]>0 .
$$

The positive sign of this derivative follows directly from equation (33) by noticing that $(1-\gamma) N^{2}>0$. A higher capital income tax rate therefore shifts the function $f(L)$ upwards.

Second, the capital income tax rate has no effect on $h(L)$. This implies that, given the existence of a unique equilibrium, the effect of the tax rate on the equilibrium value of leisure is negative. Since $h(0)>f(0)=0$ (see footnote 2), $h(L)$ (which is monotone in $L$ ) intersects $f(L)$ from above, which implies that an upward shift of $f(L)$ decreases the equilibrium value of leisure. A rise in the capital income tax rate, consequently, leads to less time spent on leisure activities, and, hence, to a rise in the rate of economic growth. 
Proposition 4 Given Condition 1, let a unique interior BGP exist. If human capital is the only input in the education sector, an increase in the tax rate on (physical) capital income induces a rise in the long-run rate of growth.

Proof. This follows immediately from the consideration preceding the proposition.

Let us now examine the more general case in which capital is an input in the education sector, i.e. $0<\beta<1$. Equation (20) reveals that in this case the capital income tax has a direct negative effect on the growth rate of $\left(1-\tau_{r}\right)^{(1-\gamma) \nu}$. The indirect effect is now more complicated as the sign of the derivative of $f(L)$ with respect to $T$ cannot be established analytically. However, extensive numerical computations ${ }^{4}$ show that $\partial f(L) / \partial T$ is positive for all $L \in(0,1)$. Then, a higher $\tau_{r}$, which implies a higher $T$, shifts $f(L)$ upwards.

Numerical Result $1 \partial f(L) / \partial T>0$ for all $L \in(0,1)$.

The effect of the capital income tax rate on $h(L)$ can be deduced from rewriting equation (19) as

$$
\begin{aligned}
h(L)= & \frac{\sigma_{\alpha}-\beta}{\sigma_{\alpha}}(1-L)+\left[\rho+\left(1-\sigma_{\alpha}\right) \delta\right] \times \\
& \times \Delta\left(1-\tau_{r}\right)^{-\nu(1-\gamma)}\left(1-\tau_{w}\right)^{-(1-\nu)(1-\beta)}(1-L)^{\nu},
\end{aligned}
$$

with $\Delta=\frac{\psi^{-(1-\nu)(1-\beta)} \beta^{\nu}}{\sigma_{\alpha} B^{1-\nu}[A(1-\gamma)]^{\nu}}$. Therefore, the effect of the capital income tax rate on $h(L)$, like in the case of the (total) income tax rate, depends on the relative values of $\sigma, \alpha, \delta$ and $\rho$ : An increase in $\tau_{r}$ induces a positive shift of $h(L)$ if $\sigma<1+\rho /(\alpha \delta)$ and a negative shift if $\sigma>1+\rho /(\alpha \delta)$.

Again we can ask ourselves the question whether the positive effect on the growth rate through a fall in the time spent on leisure activities could dominate the direct negative effect. While this was not possible in the case of income taxation, it is possible in the case of capital income taxation to construct examples in which the tax rate has a positive effect on the longrun growth rate. Moreover, it is possible for sensible or empirically plausible parameter values. For example, let $\gamma=0.67$ (consistent with data on labor's share of income); $\rho=0.05 ; \delta=0.1 ; \sigma=3$ (the elasticity of intertemporal substitution, $1 / \sigma$, is usually estimated between 0.2 and 1 , see e.g. VissingJørgenson, 2002, Mulligan, 2002); $\beta=0.95 ; \alpha=0.5 ; A=0.5 ; B=0.4$. Table 2 shows the effect of increasing $\tau_{r}$ from 0 to 0.5 on leisure $L$ and the

\footnotetext{
${ }^{4}$ The numerical computations depend on the values of $\alpha, \beta, \gamma$ and $T$, such that $0<$ $\alpha<1,0<\gamma<\beta<1$ and $T>0$.
} 
growth rate $g$, both starting from an undistorted economy $\left(\tau_{w}=0\right)$ as well as a distorted economy $\left(\tau_{w}=0.5\right)$. Notice that the finding that capital income taxation can have positive growth effects depends on the endogeneity of the leisure choice. With a fixed labor supply this result cannot be obtained.

Proposition 5 Let capital be an input in the education sector. Then there exist (sensible) configurations of the parameters such that an increase in the tax rate on capital income induces a rise in the long-run rate of growth.

Proof. This follows from numerical simulation of the model (see table 2).

The reason for this positive effect on the growth rate - or, better, the possibility of a positive effect - is that, compared to income taxation, spending time on capital accumulation, $N$, and on human capital accumulation, $1-$ $N-L$, becomes more attractive, because human capital is not taxed. Hence, leisure becomes more expensive and will be purchased less.

\subsubsection{Labor income taxation}

Let us first examine the case of $\beta=1$. Given the growth rate in equation (21) and the functions $f(L)$ and $h(L)$ (equations 33 and 34 in appendix 5.2), it is easy to see that the effect of a labor income tax is exactly the opposite of the effect of a capital income tax. A tax on labor income, therefore, induces a downward shift in $f(L)$, while leaving $h(L)$ unchanged. Under the same conditions as in the previous section, a higher tax rate on labor income will increase the time spent on leisure.

Proposition 6 Given Condition 1, let a unique interior BGP exist. If human capital is the only input in the education sector, an increase in the tax rate on labor income induces a decline in the long-run rate of growth.

Proof. Follows immediately from Proposition 4.

Considering the more general case in which capital is an input in the education sector, equation (20) directly shows that the labor income tax rate has a direct negative effect on the growth rate of $\left(1-\tau_{w}\right)^{\gamma \nu}$. The indirect effect of the labor income tax rate through leisure is very similar to the indirect effect of the capital income tax rate. First, the effect of $\tau_{w}$ on $f(L)$ is exactly the opposite from the effect of $\tau_{r}$, i.e., a higher $\tau_{w}$ shifts $f(L)$ downwards (given Numerical Result 1). Second, the effect of $\tau_{w}$ on $h(L)$ is qualitatively similar to the effect of $\tau_{r}$ and follows from equation (23): An increase in $\tau_{w}$ induces a positive shift of $h(L)$ if $\sigma<1+\rho /(\alpha \delta)$ and a negative shift if $\sigma>1+\rho /(\alpha \delta)$. 
What will be the effect of the labor income tax rate on the long-run rate of growth? If we compare labor income taxation with income taxation, the use of physical capital in the capital accumulation process is not taxed, implying that more capital is used to accumulate capital and less to accumulate human capital. This has a negative effect on growth. Moreover, the positive effect on growth through reduced leisure as present in the case of capital income taxation is absent in this case. This suggests that the effect of the labor income tax rate on the long-run rate of growth is negative. This is confirmed in the next proposition.

Proposition 7 Let Condition 1 and Numerical Result 1 hold. Suppose that there exists a unique interior BGP. Then an increase in the tax rate on labor income induces a decline in the long-run rate of growth.

Proof. See appendix 5.5.4.

Hence, increasing the tax rate on labor income reduces the long-run rate of growth. Like in the case of income taxation, the negative effect of income taxation on the long-run growth rate, compared to the situation with a fixed labor supply, is either stronger (i.e. more negative) in the case of more time spent on leisure activities or weaker (i.e. less negative) in the case of less time spent on leisure activities.

\subsection{Multiple balanced growth paths}

Suppose that there are three balanced growth paths as depicted in figure 1 . Then, according to proposition $1, \sigma<1+\frac{\rho}{\alpha \delta}$. This implies that a higher tax rate on income induces an upward shift in $\mathrm{h}(\mathrm{L})$. As a result BGP's 1 and 2 change, while BGP 3 stays the same, as is shown in figure 3 . In the new BGP 1 - the stable interior path - people have more leisure, work more in the goods sector but spend less time on education. As a result the growth rate is lower. Taxation of income also induces a shift in BGP 2 - the unstable interior path - such that less time will be spent on leisure activities, while the effect on the time spent on the production of goods is ambiguous. Due to the reduced time spent on leisure, however, it can be shown that the growth rate in the new balanced growth path is always higher than the growth rate in the old balanced growth path, while the capital-human capital ratio has fallen. The effects of income taxation on the three BGP's are summarized in the next proposition.

Proposition 8 Let Condition 1 hold. Suppose that there are three balanced growth paths as depicted in figure 1. Then an increase in the tax rate on 
income induces (i) a shift in BGP 1 such that the relating long-run rate of growth decreases, (ii) a shift in BGP 2 such that the relating long-run rate of growth increases while the capital-human capital ratio decreases, and (iii) no shift in $B G P 3$.

Proof. See appendix 5.5.5.

Observe that the result that a higher income tax implies a lower capitalhuman capital ratio in BGP 2 implies that the set of (initial) values of the capital-human capital ratio converging to the high-growth BGP - which itself has a lower growth rate - reduces.

Finally, consider the effects of the two tax rates on capital and labor income separately. Due to the fact that $\sigma$ is smaller than $1+\frac{\rho}{\alpha \delta}$, both capital income taxation as well as labor income taxation have a positive effect on $h(L)$. As shown in the previous subsections, given Condition 1 and Numerical Result 1, a higher tax rate on capital (labor) income induces an upward (downward) shift in $f(L)$. Figures 4 and 5 show the effects of positive tax rates on capital and labor income respectively on the equilibrium values of $N$ and $L$.

\section{Summary}

The present study analyses the effects of taxation on long-run growth in a two-sector endogenous growth model with (i) physical capital as an input in the education sector and (ii) leisure as an additional argument in the utility function. First, depending on the values of the parameters, the model may exhibit multiple balanced growth paths. As shown in the earlier literature, this is due to the labor-leisure choice. The inclusion of capital in the education sector does not change this conclusion. This paper gives an example where there are three balanced growth paths and, additionally, establishes the effects of taxation on the three equilibria.

Second, due to the flexibility of labor supply, taxation of (capital and/or labor) income may induce agents to spend more or less time on leisure activities, depending on the relative sizes of the substitution and income effects. In the case of income taxation, where capital and labor income are taxed equally, the resulting effect on the growth rate is negative, as in the case without endogenous leisure. The finding that endogenous leisure may strengthen or weaken the effect of income taxes on growth (without reversing the sign) is, however, also the result of including capital as an input in education. Having only human capital as an input in education implies that income taxation has no effect on the growth rate. 
In the case of capital income taxation the direction of the effect may also change. In this case, the positive effect of the increase in total non-leisure time dominates the direct negative effect of the tax rate on growth, implying that capital taxation increases the long-run growth rate. The possibility of a positive effect of capital income taxes on growth is shown to be a consequence of the labor-leisure choice. The inclusion of capital as an input in the education sector actually reduces this possibility.

Labor income taxation, on the contrary, has a negative effect on the growth rate, with or without capital as an input in the education sector. In general, with capital in the education sector, endogenous leisure may strengthen or weaken the effect of labor income taxes on growth, but does not reverse the sign.

\section{Appendix}

\subsection{The consumer optimization problem}

The Hamiltonian associated with the representative consumer's optimization problem reads

$$
\mathcal{H}=\frac{\left(C^{\alpha} L^{1-\alpha}\right)^{1-\sigma}}{1-\sigma}+\lambda \dot{K}+\mu \dot{H}
$$

where $\dot{K}$ and $\dot{H}$ are given by equations (4) and (5). The first-order conditions are:

$$
\begin{gathered}
\left(C^{\alpha} L^{1-\alpha}\right)^{-\sigma} \alpha C^{\alpha-1} L^{1-\alpha}=\lambda \\
\dot{\lambda}=\lambda \rho-\frac{\partial \mathcal{H}}{\partial K} \\
\left(C^{\alpha} L^{1-\alpha}\right)^{-\sigma}(1-\alpha) C^{\alpha} L^{-\alpha}=\mu \beta B[(1-\phi) K]^{1-\beta}[(1-N-L) H]^{\beta-1} H, \\
\dot{\mu}=\mu \rho-\frac{\partial \mathcal{H}}{\partial H} .
\end{gathered}
$$

If we define $q \equiv \frac{\mu}{\lambda}$, and make use of equations (8), (9) and (10), we can show that

$$
\frac{\dot{\lambda}}{\lambda}=\frac{\dot{\mu}}{\mu}=\rho+\delta-\left(1-\tau_{r}\right) r
$$


which implies, by equation (25), that the growth rate of consumption is given by equation (11). Furthermore, by the definition of $q$, equation (27) directly turns into equation (12). Notice that equation (29) implies that $q$ is constant.

Since $\mu$ is growing at the same rate as $\lambda$ and $H$ is growing at the same rate as $K$, the transversality condition is given by

$$
\lim _{t \rightarrow \infty}\left[e^{-\rho t} \lambda(t) K(t)\right]=0 .
$$

\subsection{Solution to the system of equations (13)-(17)}

Using equations (2) and (3), equation (13) can be rewritten as

$$
\begin{aligned}
& \left(1-\tau_{r}\right)(1-\gamma) A\left(\frac{\phi}{N}\right)^{-\gamma} x^{1-\gamma} \phi+\left(1-\tau_{w}\right) \gamma A\left(\frac{\phi}{N}\right)^{1-\gamma} x^{1-\gamma} N-z \\
= & B\left(\frac{1-\phi}{1-N-L}\right)^{1-\beta} x^{2-\beta}(1-N-L) .
\end{aligned}
$$

Note that equation (15) implies that

$$
\frac{1-\phi}{1-N-L}=(T \psi) \frac{\phi}{N}
$$

and

$$
\phi=\frac{N}{T \psi(1-N-L)+N} .
$$

Then, from equation (16), we can derive an expression of $x$, i.e.,

$$
x=\left[\frac{\left(1-\tau_{r}\right)(1-\gamma) A}{\beta B(T \psi)^{1-\beta}(1-L)}\right]^{\frac{1}{1-\beta+\gamma}} \frac{N}{\phi} .
$$

Moreover, it is easy to show that $\frac{N}{\phi}(1-N-L)=T \psi(1-L)^{2}+(1-2 T \psi)(1-$ $L) N+(T \psi-1) N^{2}$. These observations, together with equation (17), imply that equation (31) transforms to equation (18).

To derive equation (19), we rewrite equation (14) with the help of equation (10):

$$
\begin{aligned}
& \beta B(1-\phi)^{1-\beta}(1-N-L)^{\beta-1} x^{1-\beta}(1-L)-\delta-\rho \\
= & \sigma_{\alpha} B(1-\phi)^{1-\beta}(1-N-L)^{\beta} x^{1-\beta}-\sigma_{\alpha} \delta,
\end{aligned}
$$

or,

$$
\begin{aligned}
& B(1-\phi)^{1-\beta}(1-N-L)^{\beta-1} x^{1-\beta}\left[\beta(1-L)-\sigma_{\alpha}(1-N-L)\right] \\
= & \rho+\left(1-\sigma_{\alpha}\right) \delta .
\end{aligned}
$$


Inserting the expression for $x$ and simplifying yields equation (19).

If $\beta=1$, equations (18) and (19) reduce to

$$
\begin{gathered}
(1-\gamma) N^{2}+T \gamma(1-L) N-T \frac{\alpha \gamma}{1-\alpha}(1-L) L=0, \\
N=\frac{\sigma_{\alpha}-1}{\sigma_{\alpha}}(1-L)+\frac{\rho+\left(1-\sigma_{\alpha}\right) \delta}{\sigma_{\alpha} B}
\end{gathered}
$$

\subsection{The non-interior balanced growth path}

The Hamiltonian associated with the restricted optimization problem (in which $N=1-L$ ) reads

$$
\mathcal{H}=\frac{\left(C^{\alpha} L^{1-\alpha}\right)^{1-\sigma}}{1-\sigma}+\theta \dot{K}
$$

where $K$ is given by equation (4) (with $\phi=1$ and $N=1-L$ ). The first-order conditions are:

$$
\begin{gathered}
\left(C^{\alpha} L^{1-\alpha}\right)^{-\sigma} \alpha C^{\alpha-1} L^{1-\alpha}=\theta \\
\dot{\theta}=\theta \rho-\frac{\partial \mathcal{H}}{\partial K} \\
\left(C^{\alpha} L^{1-\alpha}\right)^{-\sigma}(1-\alpha) C^{\alpha} L^{-\alpha}=\theta\left(1-\tau_{w}\right) w H .
\end{gathered}
$$

Equations (36) and (38), together with (3) (with $\phi=1$ and $N=1-L$ ) imply that

$$
z=\frac{\alpha}{1-\alpha}\left(1-\tau_{w}\right) \gamma A x^{1-\gamma}(1-L)^{\gamma-1} L
$$

while the $\dot{x}=0$ and $\dot{z}=0$ equations are now given by

$$
\left(1-\tau_{r}\right)(1-\gamma) A(1-L)^{\gamma} x^{1-\gamma}+\left(1-\tau_{w}\right) \gamma A(1-L)^{\gamma} x^{1-\gamma}=z
$$

and

$$
\left(1-\tau_{r}\right) r-\delta-\rho=-\sigma_{\alpha} \delta .
$$

It is easy to show that the solution for $L$ to this set of equations is implicitly given by

$$
\left(1-\tau_{r}\right)(1-\gamma)+\left(1-\tau_{w}\right) \gamma=\frac{\alpha}{1-\alpha}\left(1-\tau_{w}\right) \gamma \frac{L}{1-L},
$$

which is exactly equal to equation (18) with $N=1-L$. 


\subsection{Stability of the balanced growth paths}

To investigate the local stability of the balanced growth paths, we first derive the law of motion of the variables $\{x, z, L, N, \phi\}$. Elimination of the costate variables leads to the following system of five differential equations:

$$
\begin{gathered}
\dot{x}=A(\phi x)^{1-\gamma} N^{\gamma}-B(1-\phi)^{1-\beta}(1-N-L)^{\beta} x^{2-\beta}-z, \\
\dot{L}=\frac{L}{1-\frac{(1-\sigma)(1-\alpha)}{\sigma_{\alpha}}}\left[\eta(x, L, N, \phi)+\frac{1-\gamma}{\beta-\gamma} \mu(x, L, N, \phi)\right], \\
\dot{z}=z\left[\eta(x, L, N, \phi)+\frac{(1-\sigma)(1-\alpha)}{\sigma_{\alpha} L} \dot{L}\right] \\
\dot{N}=N\left[\frac{1-\phi}{\phi(1-L)-N} \dot{L}+\frac{1-N-L}{\phi(1-L)-N}\left(\frac{\dot{x}}{x}+\frac{1}{\beta-\gamma} \mu(x, L, N, \phi)\right)\right], \\
\dot{\phi}=\phi(1-\phi)\left[\frac{1-L}{(1-N-L) N} \dot{N}+\frac{1}{1-N-L} \dot{L}\right]
\end{gathered}
$$

where $\eta($.$) and \mu($.$) are given by$

$$
\begin{aligned}
\eta(x, L, N, \phi)= & \frac{(1-\gamma) A}{\sigma_{\alpha}}(\phi x)^{-\gamma} N^{\gamma}-B((1-\phi) x)^{1-\beta}(1-N-L)^{\beta} \\
- & \frac{\rho+\left(1-\sigma_{\alpha}\right) \delta}{\sigma_{\alpha}}, \\
\mu(x, L, N, \phi)= & (1-L) \beta B((1-\phi) x)^{1-\beta}(1-N-L)^{\beta-1} \\
& -(1-\gamma) A(\phi x)^{-\gamma} N^{\gamma} .
\end{aligned}
$$

By differentiating each differential equation with respect to $x, z, L, N$ and $\phi$ in a steady state, we obtain the coefficients matrix of the linearized system around a steady state. The eigenvalues of this matrix determine the local stability of the steady state. If all eigenvalues have negative real parts the steady state is locally stable. If all eigenvalues have positive real parts the steady state is unstable. If some of the eigenvalues have negative and others positive real parts, there exists a stable manifold, which is defined as the 
set of points on which convergence to the steady state takes place. The dimension of the stable manifold is equal to the number of eigenvalues with negative real parts.

In the case of the three equilibria of figure 1 the (approximate) values of the eigenvalues, which are given in table 3, imply that BGP 2 is unstable, while BGP's 1 and 3 are stable, i.e. both have a stable manifold of dimension one.

\subsection{Proofs}

\subsubsection{Proof of Proposition 1}

As written in the paragraph preceding Proposition 1, the first step in the proof is to prove that $f(L)$ is strictly concave. Solving equation (18) for $N=f(L)$ yields

$$
2(1-\gamma)(1-T \psi) f(L)+(1-L) \Omega=(1-L) Q
$$

with $Q=\left(\Omega^{2}+4(1-\gamma)(1-T \psi) T\left\{(1-\gamma) \psi+\frac{\alpha \beta \gamma}{1-\alpha} \frac{L}{1-L}\right\}\right)^{1 / 2}>0$ and $\Omega=$ $\{\beta(1-\gamma+T \gamma)-(1-\gamma)(1-2 T \psi)\}$. Differentiating this equation with respect to $L$ gives

$$
2(1-\gamma)(1-T \psi) f^{\prime}(L)=\Omega-Q+\frac{2(1-\gamma)(1-T \psi) T \alpha \beta \gamma}{(1-\alpha) Q(1-L)} .
$$

Replacing $\Omega-Q$ with the expression implied by equation (42) and simplifying yields

$$
(1-L) f^{\prime}(L)=-f(L)+\frac{\alpha \beta \gamma T}{(1-\alpha) Q}
$$

which, since $Q>0$, implies that

$$
-(1-L) f^{\prime}(L)<f(L) .
$$

Using equation (43), the second derivative of $f(L)$ can be written as

$$
f^{\prime \prime}(L)=\frac{-2(1-\gamma)(1-T \psi)(\alpha \beta \gamma T)^{2}}{(1-\alpha)^{2}(1-L)^{3} Q^{3}}<0
$$

This proves that $f(L)$ is strictly concave.

The second step is to find out when $h(L)$ is convex and/or concave. It is straightforward to show that the second derivative of $h(L)$ is given by

$$
h^{\prime \prime}(L)=-\nu(1-\nu) \frac{\left(\rho+\left(1-\sigma_{\alpha}\right) \delta\right)(T \psi)^{-(1-\nu)(1-\beta)} \beta^{\nu}}{\sigma_{\alpha} B^{1-\nu}\left[\left(1-\tau_{r}\right) A(1-\gamma)\right]^{\nu}}(1-L)^{\nu-2} .
$$

Hence, $h(L)$ is strictly concave if $\sigma<1+\frac{\rho}{\alpha \delta}$ and strictly convex if $\sigma>1+\frac{\rho}{\alpha \delta}$. 


\subsubsection{Proof of Lemma 2}

From equation (32) we derive that

$$
x(L, N)=X_{0}[T \psi(1-L)+(1-T \psi) N](1-L)^{\frac{-1}{1-\beta+\gamma}},
$$

with $X_{0} \equiv\left[\frac{\left(1-\tau_{r}\right)(1-\gamma) A}{\beta B(T \psi)^{1-\beta}}\right]^{\frac{1}{1-\beta+\gamma}}>0$. This implies that

$$
x(L, f(L))=\eta_{1}(1-L)^{\frac{\gamma-\beta}{1-\beta+\gamma}}+\eta_{2} f(L)(1-L)^{\frac{-1}{1-\beta+\gamma}},
$$

with $\eta_{1} \equiv X_{0} T \psi>0$ and $\eta_{2} \equiv X_{0}(1-T \psi)>0$ (by Condition 1$)$. Differentiating with respect to $L$ yields

$$
\begin{aligned}
\frac{\partial x(L, f(L))}{\partial L}= & \eta_{1} \frac{\beta-\gamma}{1-\beta+\gamma}(1-L)^{\frac{-1}{1-\beta+\gamma}}+\eta_{2} f^{\prime}(L)(1-L)^{\frac{-1}{1-\beta+\gamma}} \\
& +\eta_{2} \frac{1}{1-\beta+\gamma} f(L)(1-L)^{\frac{-1}{1-\beta+\gamma}-1}
\end{aligned}
$$

This derivative is positive iff

$$
\eta_{1} \frac{\beta-\gamma}{1-\beta+\gamma}+\eta_{2} f^{\prime}(L)+\eta_{2} \frac{1}{1-\beta+\gamma} f(L)(1-L)^{-1}>0,
$$

which is true since equation (44) implies that

$$
-f^{\prime}(L)<\frac{1}{1-\beta+\gamma} f(L)(1-L)^{-1}
$$

since $\frac{1}{1-\beta+\gamma}>1$.

\subsubsection{Proof of Proposition 3}

Inserting $\tau_{w}=\tau_{r} \equiv \tau$ into equation (20) implies that the growth rate as a function of $L$ reads

$$
g(L)=G(1-\tau)^{\nu}(1-L)^{1-\nu}-\frac{\rho+\delta}{\sigma_{\alpha}} .
$$

The derivative with respect to $\tau$ is, then, given by

$$
\frac{\partial g(L)}{\partial \tau}=-\nu G(1-\tau)^{\nu-1}(1-L)^{1-\nu}-(1-\nu) G(1-\tau)^{\nu}(1-L)^{-\nu} \frac{\partial L}{\partial \tau},
$$

which implies that $\frac{\partial g}{\partial \tau}<0$ iff

$$
\frac{\partial L}{\partial \tau}>-\frac{\nu}{1-\nu}\left(\frac{1-L}{1-\tau}\right) \equiv-\frac{1-\beta}{\gamma}\left(\frac{1-L}{1-\tau}\right) .
$$


To prove the proposition we will show that this inequality is satisfied.

The total derivative of $f(L)=h(L)$, which applies in a balanced growth path, can be written as

$$
\left(f^{\prime}(L)-h^{\prime}(L)\right) \frac{\partial L}{\partial \tau}=\frac{\partial h(L)}{\partial \tau} .
$$

Let $h(L)=H_{0}(1-L)+H_{1}(1-\tau)^{-\nu}(1-L)^{\nu}$, where $H_{0}$ and $H_{1}$ can be deduced from equation (19). Then

$$
\frac{\partial h(L)}{\partial \tau}=\nu H_{1}(1-\tau)^{-\nu-1}(1-L)^{\nu}
$$

and

$$
-h^{\prime}(L)=H_{0}+\nu H_{1}(1-\tau)^{-\nu}(1-L)^{\nu-1} .
$$

This implies that

$$
\left(\frac{1-\tau}{1-L}\right) \frac{\partial L}{\partial \tau}=\frac{\nu H_{1}(1-\tau)^{-\nu}(1-L)^{\nu-1}}{f^{\prime}(L)+H_{0}+\nu H_{1}(1-\tau)^{-\nu}(1-L)^{\nu-1}},
$$

which should be higher than $-\frac{\nu}{1-\nu}$ to satisfy equation (54). Hence, equation (54) is satisfied iff

$$
\frac{(1-\nu) H_{1}(1-\tau)^{-\nu}(1-L)^{\nu-1}}{f^{\prime}(L)+H_{0}+\nu H_{1}(1-\tau)^{-\nu}(1-L)^{\nu-1}}>-1 .
$$

In the case of a unique interior BGP, $h(L)$ intersects $f(L)$ from above, implying that $f^{\prime}(L)-h^{\prime}(L)>0$. This allows us to multiply both sides of equation (59) with $f^{\prime}(L)-h^{\prime}(L)$ which yields

$$
f^{\prime}(L)+H_{0}>-H_{1}(1-\tau)^{-\nu}(1-L)^{\nu-1},
$$

or

$$
-f^{\prime}(L)<H_{0}+H_{1}(1-\tau)^{-\nu}(1-L)^{\nu-1}=\frac{h(L)}{1-L}=\frac{f(L)}{1-L} .
$$

According to equation (44) this inequality is satisfied.

\subsubsection{Proof of Proposition 7}

This proof proceeds along the same lines as the proof of proposition 3. First, it is easy to show that $\frac{\partial g}{\partial \tau_{w}}<0$ iff

$$
\frac{\partial L}{\partial \tau_{w}}>-\frac{\gamma \nu}{1-\nu}\left(\frac{1-L}{1-\tau_{w}}\right) \equiv-(1-\beta)\left(\frac{1-L}{1-\tau_{w}}\right) .
$$


Then we take the total derivative of $f(L)=h(L)$, which can be written as

$$
\left(f^{\prime}(L)-h^{\prime}(L)\right) \frac{\partial L}{\partial \tau_{w}}=\frac{\partial h(L)}{\partial \tau_{w}}-\frac{\partial f(L)}{\partial \tau_{w}} .
$$

Two observations are made at this point. First, by Numerical Result 1, $\frac{\partial f(L)}{\partial \tau_{w}}<0$. Second, in the case of a unique interior BGP, $h(L)$ intersects $f(L)$ from above, which implies that $f^{\prime}(L)-h^{\prime}(L)>0$. These two observations imply that

$$
\frac{\partial L}{\partial \tau_{w}}>\frac{\partial h(L) / \partial \tau_{w}}{f^{\prime}(L)-h^{\prime}(L)}
$$

which can be rewritten as

$$
\left(\frac{1-\tau_{w}}{1-L}\right) \frac{\partial L}{\partial \tau_{w}}>\frac{(1-\nu)(1-\beta) H_{1}\left(1-\tau_{w}\right)^{-(1-\nu)(1-\beta)}(1-L)^{\nu-1}}{f^{\prime}(L)+H_{0}+\nu H_{1}\left(1-\tau_{w}\right)^{-(1-\nu)(1-\beta)}(1-L)^{\nu-1}} .
$$

If the right-hand side of this inequality is higher than $-(1-\beta)$, i.e.,

$$
\begin{aligned}
& (1-\nu)(1-\beta) H_{1}\left(1-\tau_{w}\right)^{-(1-\nu)(1-\beta)}(1-L)^{\nu-1} \\
> & -(1-\beta)\left[f^{\prime}(L)+H_{0}+\nu H_{1}\left(1-\tau_{w}\right)^{-(1-\nu)(1-\beta)}(1-L)^{\nu-1}\right],
\end{aligned}
$$

equation (62) is satisfied and the proof is done. It is easy to show that this inequality can be transformed to

$$
-f^{\prime}(L)<\frac{h(L)}{1-L}=\frac{f(L)}{1-L}
$$

which is satisfied according to equation (44).

\subsubsection{Proof of proposition 8}

First, observe that in BGP $1, f^{\prime}(L)-h^{\prime}(L)>0$. This implies that this case is similar to the case of a unique interior BGP as worked out in the proof of Proposition 3, implying that a marginal increase in the tax rate decreases the long-run growth rate. Second, reasoning along the same lines as in the proof of Proposition 3 shows that, since $f^{\prime}(L)-h^{\prime}(L)<0$ in BGP 2, a marginal increase in the tax rate increases the long-run growth rate. Obviously BGP 3 is unchanged.

To find the effect of the tax rate on the capital-human capital ratio we calculate the derivative of $x(L, f(L))$ (see equation 48 ):

$$
\begin{aligned}
\frac{\partial x(L, f(L))}{\partial \tau}= & \frac{\partial \eta_{1}}{\partial \tau}(1-L)^{-\frac{\beta-\gamma}{1-\beta+\gamma}}+\frac{\partial \eta_{2}}{\partial \tau} f(L)(1-L)^{-\frac{1}{1-\beta+\gamma}}+ \\
& {\left[\frac{\eta_{1}(\beta-\gamma)}{1-\beta+\gamma}(1-L)^{-\frac{1}{1-\beta+\gamma}}+\frac{\eta_{2}}{1-\beta+\gamma} f(L)(1-L)^{-\frac{1}{1-\beta+\gamma}-1}\right]\left(\frac{\sigma L}{\partial \tau}\right) }
\end{aligned}
$$


Since $\beta>\gamma, \frac{\partial \eta_{i}}{\partial \tau}<0$ for $i=1,2$ and $\frac{\partial L}{\partial \tau}<0$ in BGP 2 (the shift in BGP 2 reduces the time spent on leisure), the capital-human capital ratio $x$ falls.

\subsection{Derivation of the growth rate as a function of $L$}

Equation (2) implies that

$$
\begin{aligned}
\left(1-\tau_{r}\right) r & =\left(1-\tau_{r}\right)(1-\gamma) A\left[\frac{\phi}{N} x\right]^{-\gamma} \\
& =\beta B\left[\frac{(1-\phi)}{1-N-L} x\right]^{1-\beta}(1-L) \\
& =\beta B(T \psi)^{1-\beta}\left(\frac{\phi}{N}\right)^{1-\beta} x^{1-\beta}(1-L)
\end{aligned}
$$

where the second and third equations follow from equations (15) and (16) respectively. Inserting the expression for $x$ as given by equation (32), yields

$$
\left(1-\tau_{r}\right) r=\psi^{(1-\beta)(1-\nu)}(\beta B)^{1-\nu}((1-\gamma) A)^{\nu}\left(1-\tau_{r}\right)^{\nu} T^{(1-\beta)(1-\nu)}(1-L)^{1-\nu} .
$$

Inserting this equation into equation (11) yields the growth rate as a function of $L$ as given in equation (20).

\section{References}

[1] Carey, D. and H. Chilinguirian (2000), "Average effective tax rates on capital, labor and consumption", OECD Economics Department Working Paper no. 258.

[2] Chamley, C. (1992), "The welfare cost of taxation and endogenous growth", Institute for Economic Development Discussion Paper No. 30, Boston University.

[3] De Hek, P.A. (1998), "An aggregative model of capital accumulation with leisure-dependent utility", Journal of Economic Dynamics and Control 23/2, 255-276.

[4] De Hek, P.A. (1999), "Endogenous technological change with leisuredependent utility", Economic Theory 14, 669-684. 
[5] Hendricks, L. (1999), "Taxation and Long-Run Growth", Journal of Monetary Economics, 43, 411-434.

[6] Jones, L.E., R. Manuelli and P. Rossi (1993), "Optimal taxation in models of endogenous growth", Journal of Political Economy 101, 485517.

[7] King, R.G., Plosser, C.I. and S.T. Rebelo (1988), "Production, growth and business cycles: I. The basic neoclassical model", Journal of Monetary Economics 21, 195-232.

[8] Ladrón-de-Guevara, A., Ortigueira, S. and M.S. Santos (1997), "Equilibrium dynamics in two-sector models of endogenous growth", Journal of Economic Dynamics and Control 21, 115-143.

[9] Lucas, R.E., Jr. (1988), "On the mechanics of economic development", Journal of Monetary Economics 22, 3-42.

[10] Lucas, R.E., Jr. (1990), "Supply-side economics: An analytical review", Oxford Economic Papers 42, 293-316.

[11] Mino, K. (1996), "Analysis of a two-sector model of endogenous growth with capital income taxation", International Economic Review 37, 227251.

[12] Mulligan, C.B. (2002), "Capital, interest, and aggregate intertemporal substitution", NBER Working Paper 9373.

[13] Ortigueira, S. (1998), "Fiscal policy in an endogenous growth model with human capital accumulation", Journal of Monetary Economics 42, 323-355.

[14] Rebelo, S. (1991), "Long-run policy analysis and long-run growth", Journal of Political Economy 99, 500-521.

[15] Smith, W.T. (1996), "Taxes, uncertainty, and long-term growth", European Economic Review 40, 1647-1664.

[16] Stokey, N.L. and S. Rebelo (1995), "Growth effects of flat-rate taxes", Journal of Political Economy 103, 519-550.

[17] Uhlig, H. and N. Yanagawa (1996), "Increasing the capital income tax may lead to faster growth", European Economic Review 40, 1521-1540. 


\section{Table 1. Average Effective Tax Rates ${ }^{1}, 1991-1997$}

Per cent

$\begin{array}{lccc} & \text { capital income }\left(\tau_{r}\right) & \text { labor income }\left(\tau_{w}\right) & T \equiv \frac{1-\tau_{w}}{1-\tau_{r}} \\ \text { Australia } & 28.0 & 22.6 & 1.21 \\ \text { Austria } & 18.9 & 41.8 & 0.72 \\ \text { Belgium } & 30.8 & 39.7 & 0.87 \\ \text { Canada } & 38.6 & 28.7 & 1.16 \\ \text { Denmark } & 29.1^{2} & 42.8 & 0.81 \\ \text { Finland } & 19.6 & 44.5 & 0.69 \\ \text { France } & 23.6 & 40.2 & 0.78 \\ \text { Germany } & 19.9 & 35.9 & 0.80 \\ \text { Greece } & 26.8 & 24.3 & 1.03 \\ \text { Ireland } & 18.7 & 25.1 & 0.92 \\ \text { Italy } & 31.0 & 36.3 & 0.92 \\ \text { Japan } & 32.6 & 24.0 & 1.13 \\ \text { Netherlands } & 24.7 & 41.0 & 0.78 \\ \text { New Zealand } & 34.9 & 24.2 & 1.16 \\ \text { Norway } & 20.2 & 35.5 & 0.81 \\ \text { Portugal } & 18.3 & 22.7 & 0.95 \\ \text { Spain } & 20.6 & 30.4 & 0.88 \\ \text { Sweden } & 30.5 & 48.5 & 0.74 \\ \text { Switzerland } & 25.1 & 30.2 & 0.93 \\ \text { U.K. } & 38.4 & 21.0 & 1.28 \\ \text { U.S.A. } & 31.1 & 22.6 & 1.12 \\ & & & \\ \text { Simple average } & 26.7 & 32.5 & 0.92\end{array}$

1. The average effective tax rates on capital and labor income are taken from Carey and Tchilinguirian (2000, Table 4) using the revised methodology.

2. Denmark's capital income tax rate is for 1991-1996.

Table 2. The effect of capital income taxation

$$
\begin{array}{ccccc} 
& \tau_{w}=0 & \tau_{w}=0 & \tau_{w}=0.5 & \tau_{w}=0.5 \\
& \tau_{r}=0 & \tau_{r}=0.5 & \tau_{r}=0 & \tau_{r}=0.5 \\
L & 0.32 & 0.31 & 0.35 & 0.32 \\
g & 0.037 & 0.038 & 0.029 & 0.032
\end{array}
$$


Table 3. The (approximate) eigenvalues of the three BGP's

\begin{tabular}{lll} 
BGP 1 & \multicolumn{1}{c}{ BGP 2 } & BGP 3 \\
0.055 & 0.052 & 0.073 \\
0.027 & $0.027+0.033 \mathrm{i}$ & -0.006 \\
0 & $0.027-0.033 \mathrm{i}$ & 0 \\
-0.028 & 0 & \\
0 & 0 &
\end{tabular}




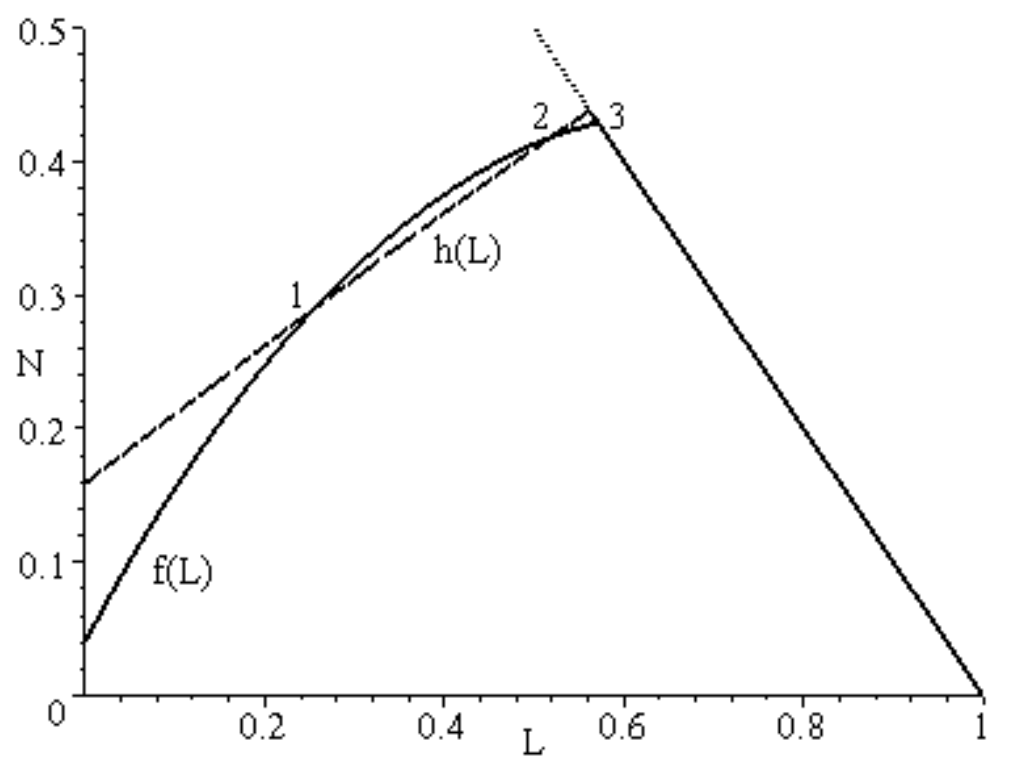

Figure 1: An example of multiple equilibria $(\alpha=0.6, \beta=0.96, \gamma=0.5$, $\left.A=1.8, B=0.106, \rho=0.03, \sigma=0.35, \delta=0.05, \tau_{r}=\tau_{w}=0\right)$. 


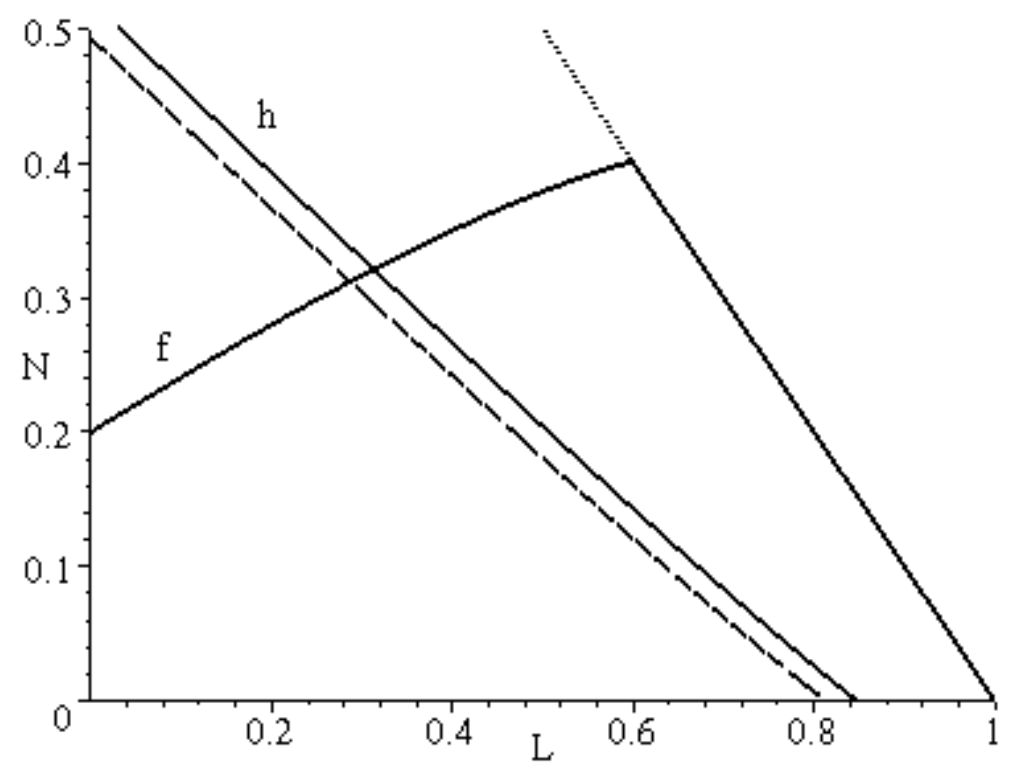

Figure 2: An example of the effect of income taxation on the unique BGP $(\alpha=0.5, \beta=0.8, \gamma=0.67, A=0.2, B=0.4, \rho=0.05, \sigma=4, \delta=0.1$, $\left.\tau_{r}=\tau_{w}=0, \tau_{r}^{\prime}=\tau_{w}^{\prime}=0.5\right)$. 


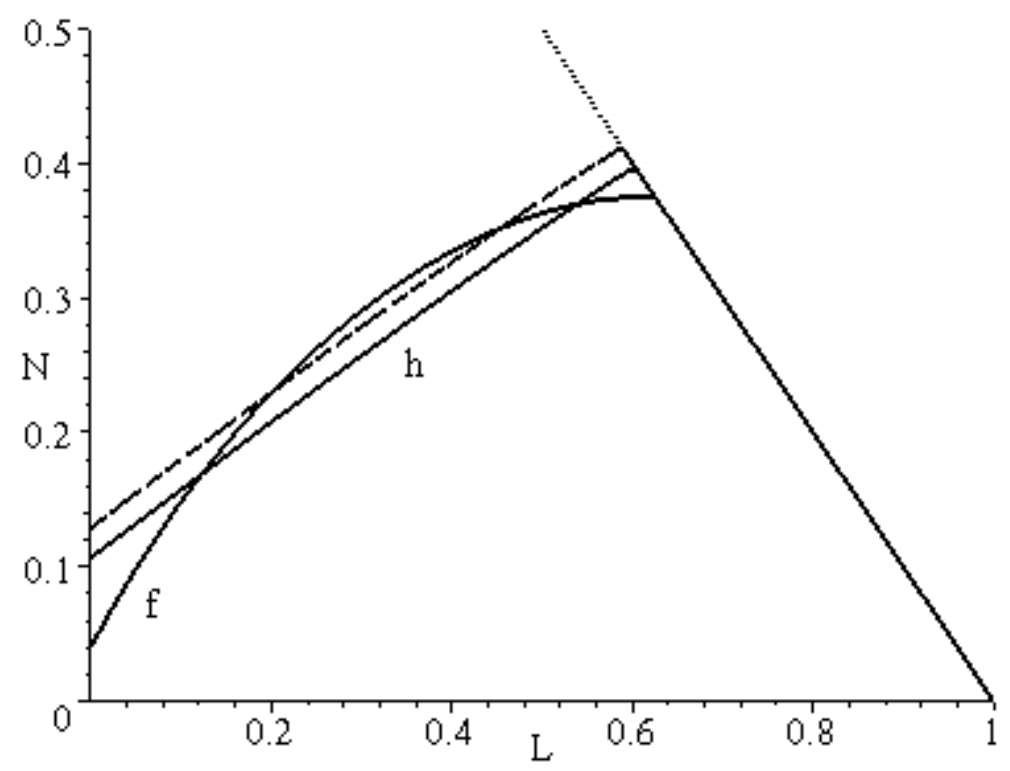

Figure 3: An example of the effect of income taxation on the three BGP's $(\alpha=0.6, \beta=0.96, \gamma=0.4, A=1.8, B=0.11, \rho=0.03, \sigma=0.35, \delta=0.05$, $\left.\tau_{r}=\tau_{w}=0, \tau_{r}^{\prime}=\tau_{w}{ }^{\prime}=0.3\right)$. 


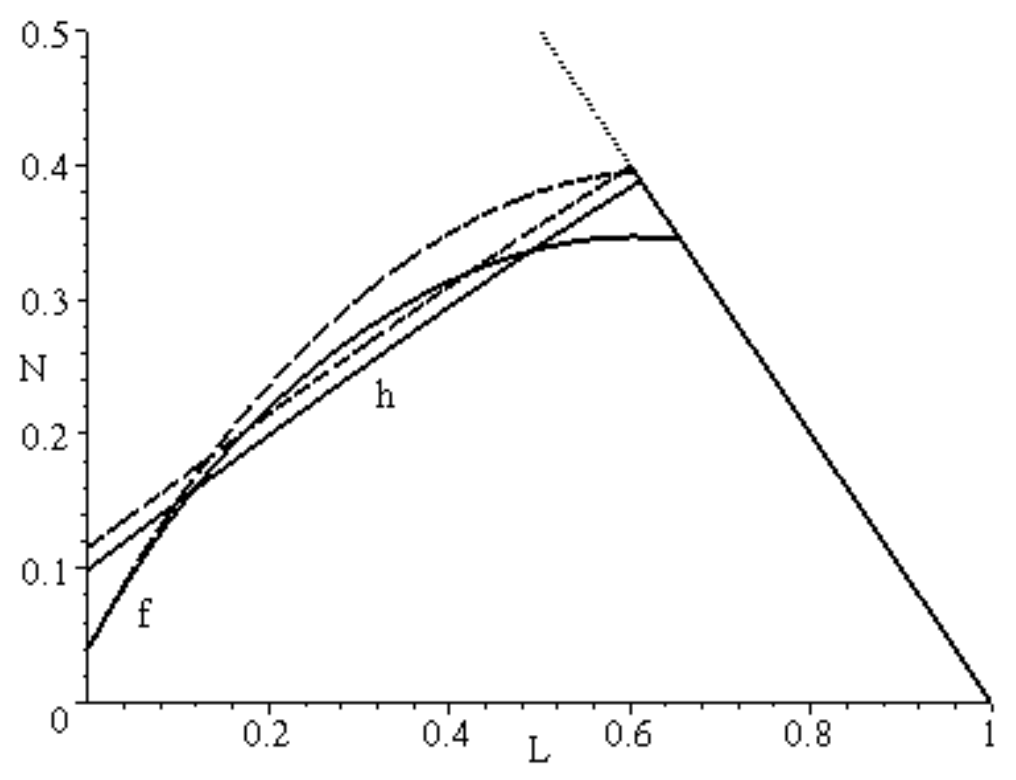

Figure 4: An example of the effect of capital income taxation on the three BGP's $(\alpha=0.6, \beta=0.96, \gamma=0.35, A=1.5, B=0.11, \rho=0.03, \sigma=0.35$, $\left.\delta=0.05, \tau_{r}=\tau_{w}=0, \tau_{r}{ }^{\prime}=0.3\right)$. 


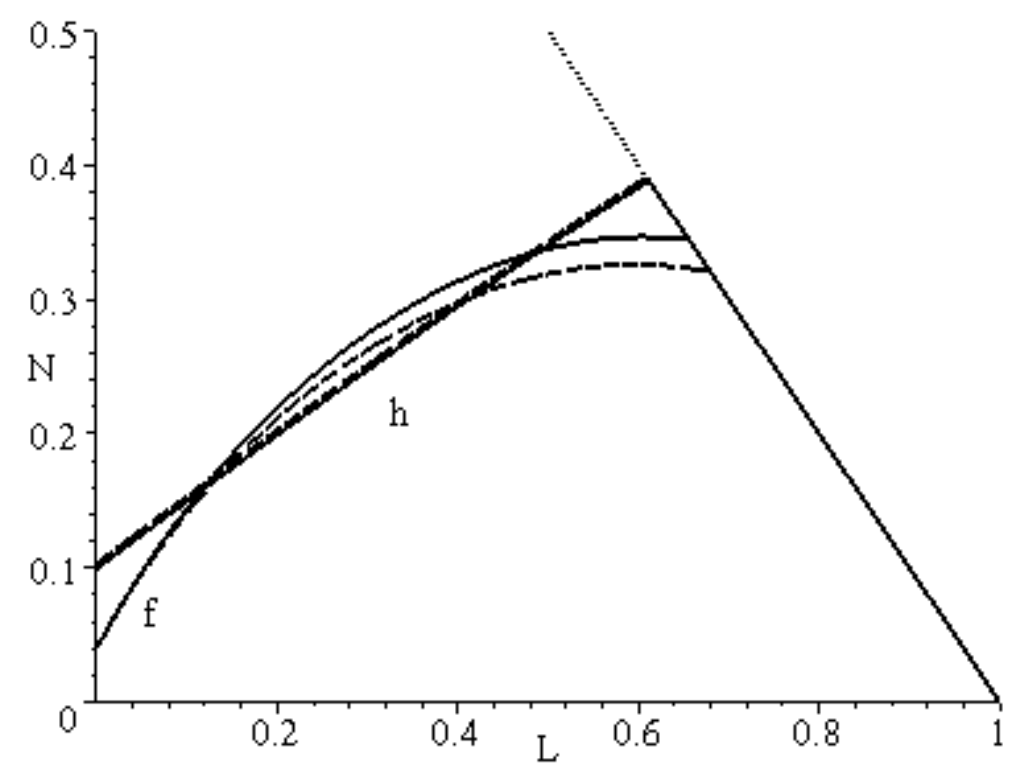

Figure 5: An example of the effect of labor income taxation on the three BGP's $(\alpha=0.6, \beta=0.96, \gamma=0.35, A=1.5, B=0.11, \rho=0.03, \sigma=0.35$, $\left.\delta=0.05, \tau_{r}=\tau_{w}=0, \tau_{w}^{\prime}=0.15\right)$. 